\title{
Impact of Social Media Advertising On Indian Energy Drink Market
}

\author{
Chandan Thakur $^{1 *}$, Ritika Roy ${ }^{2}$, Sourav Guha Ray ${ }^{3}$ \\ ${ }^{1}$ Associate Professor, Department of Marketing, Universal Business School, Karjat, India \\ ${ }^{2,3}$ Student,Universal Business School, Karjat, India \\ *Corresponding author: chandan_t@yahoo.com
}

\begin{abstract}
We have addressed the present study, which discusses the impact on customer brand preferences of social media advertising. Social networking as an immersive business environment where marketers and brand managers can better engage with, communicate and impact consumer decision making (high-energy drinks) on products. This is so important. The new challenge of marketers is to realize that customer-led marketing is a significant marketing feature. When everybody searches for a health alternative in this new situation. All try to keep foot. This is an incentive for the energy drink industry to eventually expand.

In the 2020-2025 forecast period, the Indian energy drink market is projected to expand in the CAGR by $9.22 \%$. Energy drinks such as Red Bull, Gatorade, Sting and Mountain Dew are popular. All businesses attract customers through diverse tactics such as cutting prices, promoting celebrities and funding various sports. These businesses have continued to impact people in the rising Energy Drink market. Social media's influence is huge. Social networking ads is the upcoming medium for both businesses to try to build a footprint. Red Bull and Mountain Dew, who have done outstanding marketing work and are still involved in the social media.
\end{abstract}

Keywords: Social media advertising, Red Bull social media pages, Mountain Dew social media pages, Gatorade social media pages, Sting social media pages, Glucon D social media pages, Engagement rate, Endorsements, Brand awareness.

\section{Introduction}

Energy drink, any drink that contains high levels of ingredients, usually caffeine, as well as sugar and sometimes supplements, such as vitamins or carnitine, and that is advertised as a substance capable of improving mental alertness and physical efficiency.

Energy drinks vary from sports drinks that are used to substitute water and electrolytes during or after physical exercise, and from coffee and tea that are blended, which contain less ingredients and can be decaffeinated. Energy drinks are also distinct from soft drinks, which either do not contain caffeine or contain very small quantities of caffeine. While some energy drinks are considered beverages, others, including those containing food additives (e.g. taurine or other amino acids), can be sold as dietary supplements.

\section{A. Background}

Energy drinks were an influential branch of the early soft drinks industry; Pepsi, for example, was initially sold as an energy booster. The name Coca-Cola was derived from its two active ingredients, both known stimulants: coca leaves and kola nuts (a source of caffeine). Fresh coca leaves were replaced by 'spent' leaves in 1904 due to fears about the use of cocaine in food products; federal lawsuits United States v. Forty Barrels and Twenty Kegs of Coca-Cola and subsequent litigation forced The Coca-Cola Corporation to reduce the amount of caffeine in its formula by 1916, While the Food and Drug Administration eventually lost the case against the inanimate Coca-Cola barrels because it failed to show that the levels of caffeine in the beverage- $78 \mathrm{mg}$ per 8 flow, equivalent to modern energy drinks at the time of the lawsuit - were unsafe as stated.

In the United Kingdom, Lucozade Energy was first marketed as a hospital drink for "recovery assistance" in 1929; in the early 1980s, it was advertised as an energy drink for "recovery of lost energy."

In Japan, the energy drink dates back at least as far back as the early 1960s, when the Lipovitan brand was introduced.

In 1985, Jolt Cola was introduced in the United States. Its marketing strategy centered on the drink's caffeine content, billing it to promote wakefulness. The drink's initial slogan read: "All the sugar and twice the caffeine.

In 1995, PepsiCo launched Josta, the first energy drink produced by a major US-based soda corporation (one with interests beyond energy drinks), but Pepsi discontinued the product in 1999.Pepsi would later return to the energy drink market with the AMP brand.

In Europe, energy drinks were pioneered by Lisa and a product called "Power Horse" before Dietrich Mateschitz, an Austrian entrepreneur, launched Red Bull, the world's bestseller in the 21 st century. Mateschitz created Red Bull based on a Thai drink named Krating Daeng, based on Lipovitan. After its introduction in 1997, Red Bull became the leading brand in the US with a market share of about $47 \%$ in 2005.

In New Zealand and Australia Frucor Beverages has launched the leading energy drink commodity in those countries. The commodity now accounts for more than $60 \%$ of the market in New Zealand and Australia. 


\section{B. Topmost energy drinks available in India}

There are many companies who are introduced beverages which contains high level of caffeine and sugar, introduced as energy drink. Some popular energy drinks are like,
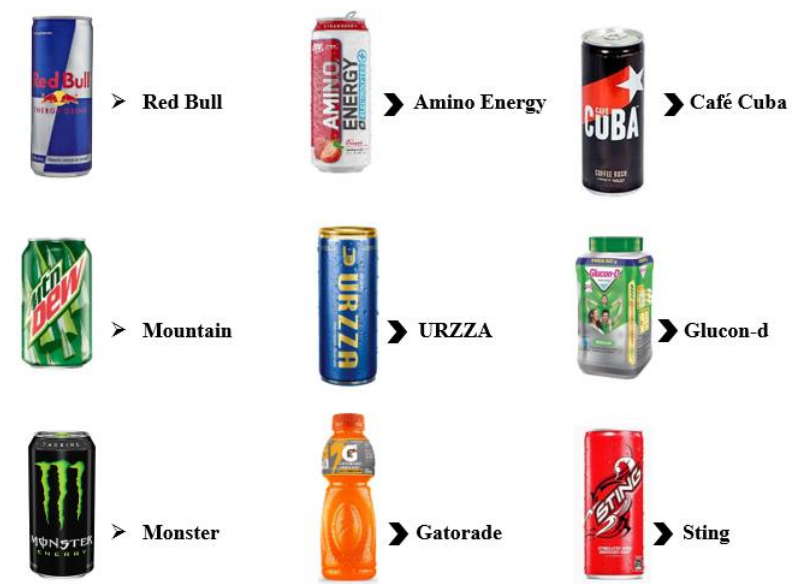

\section{Indian Energy Drink Market:}

Energy drinks are caffeine beverage products that surpass $145 \mathrm{mg}$ of caffeine per litre. The products are sold as nonalcoholic drinks that are used to improve energy intake. Increased demand for energy boosters from young people in parties and clubs is increasing demand for energy drinks in India. Consumers have become more conscious, which in turn has increased the market for functional drinks instead of noncarbonated drinks, which contain high calories.

While traditional and home-made drinks remain popular, the demand for non-carbonated packaged beverages has gained immense popularity over the last two years, with an annual growth of 35 per cent from 2015 to the next three years. As a result, numerous factors, such as rising disposable incomes and growing health awareness, are contributing to a rise in demand for non-carbonated beverages. This growth allows industry players to focus more on health and energy drinks, thus increasing the demand for energy drinks.



The Indian Energy Drink market is expected to rise at a CAGR of $9.22 \%$ over the $2020-2025$ forecast period.

The Indian energy drink industry is experiencing a rapid growth that has led to a fiery competition on the market. But the market is dominated by a few foreign brands. Value is not to be compromised; therefore, companies are priced low yet promising quality goods in order to gain substantial market share. Red Bull is the giant that dominates this market and continues to be the leader. With energy drinks on the street, athletes and fitness-freak customers are looking forward to new tastes in the group. Companies with goods in this segment are gaining and implementing strategies to retain their role by launching new variants in the category.

\section{Literature Review}

Patient Rambe \& Retumetse Joyce Jafeta in their article "Impact of Social Media Advertising on High Energy Drink Preferences and Consumption" attampeted to explore the impact of social media advertising on energy drink on the prospective of US energy drink market.

\section{Research and Analysis}

For this research paper we research on five energy which are very popular and famous in India. These energy drinks are Red Bull, Mountain Dew, Gatorade, Sting, Glucon D. We researched that how they launched in India and how they use their social media as a marketing tool. We researched every social media pages of these pages of these energy drinks which are maintained above.

The objectives of our study are maintained below:

1. To examine the nature and extent of the promotional strategies of energy drinks on digital media platform.

2. To investigate how digital marketing of energy drinks influence young adults.

In the 2020-2025 prediction period, the CAGR demand for Indian energy drinks will increase by 9,22 percent. Popular power drinks are available, such as Red Bull, Gatorade, Sting, Mountain Dew. All businesses rely on customers using various tactics such as spending savings, celebrity patronage and sports sponsorship. In today's economy, social media is an important weapon. It had a real influence on the demand for energy drinks. Link to the Home account.

\section{Research Methodology}

The purpose of the study is to explore the relationships among social media networks, social media advertising, promotional strategies, and energy drink market in India.

The research is completely based on the secondary research, theoretical data and observations. The whole structure throws some light on the impact of social media marketing on Indian energy drink market.

\section{Influence of Social Media Marketing on Indian Energy Drink Market}

The growing role of the social media in business advertising has allowed businesses to develop new means of communicating that can be targeted as a potential demographic for current customers and prospective consumers. Social media channels may be used to support brands in order to manipulate customer choices. Therefore, the visibility of social media 
implies that buyers can improve their brand familiarity and online recognition by mediating the impact of social media coverage. The influencing of customer behaviour is one of the key fields of publicity in social media. For instance, marketing promises of performance enhancements, concentration, reaction speed and metabolism are made in the selling of energy drinks, such as Red Bull. In comparison, mental seduction expresses itself in misleading consumers into thinking they can satisfy the mentioned wishes by consuming more energy drinks. Moreover, in exploiting consumers, mental seduction manifests that drinking more energy drinks will help them remember the specified wishes.

The energy drinks which are fall under these three categories are described below:

\section{A. Red Bull \\ 1) Red Bull Journey in India}

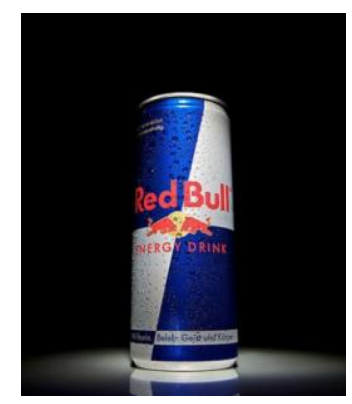

Red Bull is an energy drink. The Austrian company Red Bull $\mathrm{GmbH}$ is the signature label. It is founder of energy drink products around the world. In 2003, the brand arrived in India. The brand remains poor in contrast with the Cola majors. In the Indian market, Red Bull developed an energy drink segment. Red Bull is the global pioneer in the field of energy drinks.

The key groups of RB's target audiences are 15 to 60 years of age. High sugar energy drinks are more popular among children and women, whereas high taste and flavour energy drinks are favoured more by male customers. energy drinks Latest reports have also shown that $65 \%$ of the energy beverages industry is made up of male users.

Based on the Red Bull Hindustan times survey, sales last year grew so much (2019) that almost every human on earth could have been supplied with a package of his nameable drinks by the Austrian energy drink manufacturer. Sales in developing markets such as Brazil, India and Africa rose to a total of 7.5 billion cans worldwide last year. The Austrian company Fuschl sold over 20 million cans per day in 2019 on average. An hour this is about 850,000 cans. In India, growth has been highest, revenues have increased by $37 \%$.

\section{2) Social media marketing of Red bull}

Red Bull is the brand with 48 Million Likes on Facebook, 143.5 K Followers on Twitter and $136 \mathrm{~K}$ Followers on Instagram (Red Bull India Instagram page) as far as Social Media is concerned. The presence of Red Bull Social Media is everywhere. It operates regularly and recognizes the type of advertising on each Media Network in all promotional efforts for Digital Marketing.

Red Bull is a social media practitioners team that trains, develops and follows the latest techniques in social media marketing and incorporates social media with each project. Their social media approach is not about alcohol but sports, adventure and lifestyles, since they know people are not interested in commercials, but interested in material and images enticing them and what they want to share \& chat about. They have periodically updated their blogs on the Red Bull has taken over Social Media Sites by means of its eye-catching icons and written posts that make it more appealing to customers who can't scroll down without looking them up Media Channels by its eye-catching graphics \& Copy writing posts, which have made it more attractive \& user can't just scroll down without checking them up.

3) Red Bull Facebook

In the image, we can see the Red Bull's Facebook Page, one of Videos having 5.1k, 9.4k, 273, Likes \& 584.2k, 67K, 766.4k views and in their recent post means 21 st July 2020 they got 3.9k Likes, 463 comments \& 518 Shares. So, this shows their high quality \& rich content posts that are posted keeping in mind the likes of their audience.

Reb bull organize many events and competitions about sports and adventures because people realize that commercials are not important, they are fascinated by fascinating contents and visual messages, and what the people would like to share. Virtual Rubik's World Cup 2020 (left side picture) is also an event which organized by Reb bull and the likes (5.3k), comments (493) and shares (605) proves the high engagement of audience. This helps to create more brand awareness.

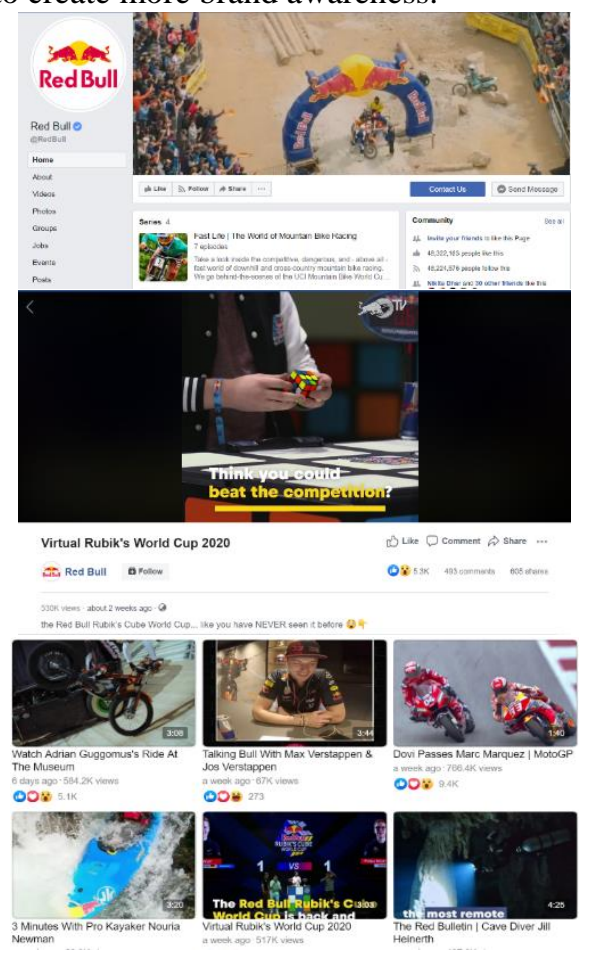




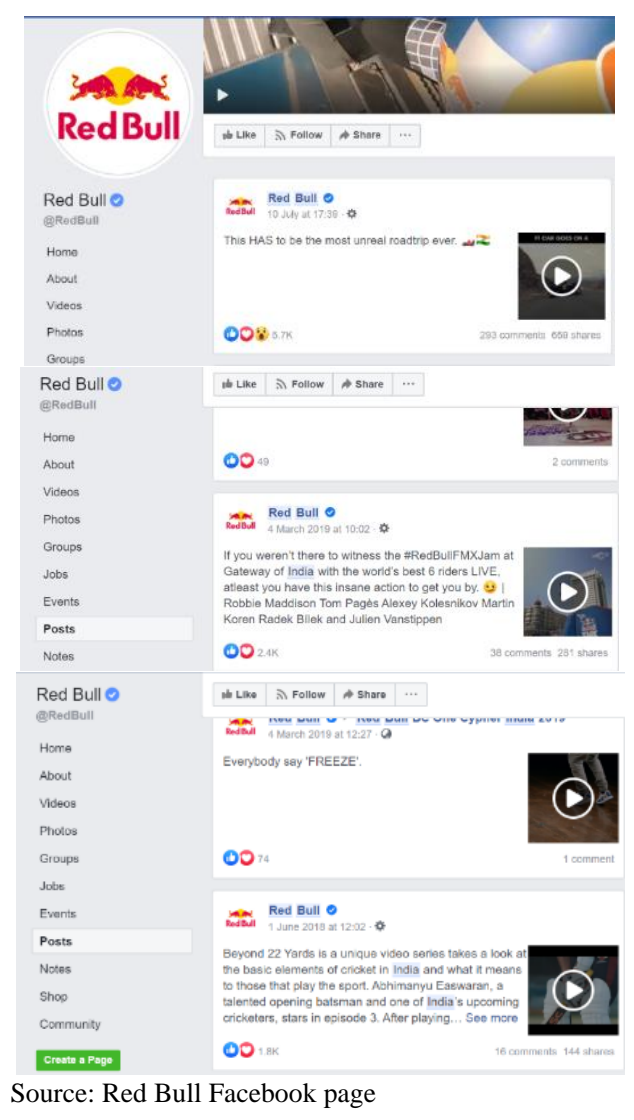

As seen in the photos above, there are a number of updates on Red Bull's Facebook page of Indian activities. The dedication rate of these posts is very high, as you can see. These rates show that both Indians and customers worldwide know Red Bull and really enjoy this sort of content. The Red Bull will expand its distribution around the world with such content.

4) Red bull Instagram

Red Bull's eye-catching graphics \& copy writing posts captured social media platforms, which made them more appealing and allowed the user not just to scroll down without scanning.

Red bull India till now (08.09.2020) Red Bull India posted 4,327 posts and got $137 \mathrm{k}$ followers on their Red Bull India Instagram page. Through their Instagram pages they promote those famous sports person with whom they endorsed their Brand.

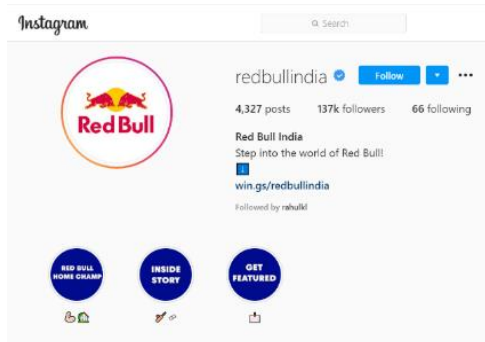

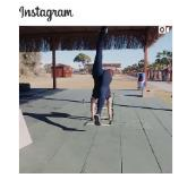
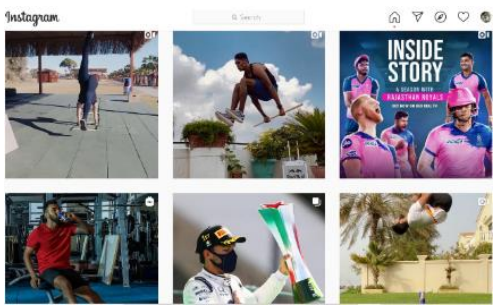

In this month of September when Dream 11 IPL is about to start Red Bull India promote a campaign \#RedBullTV where supports of Rajasthan Royals can watch the inside stories of their favourite players. In India cricket is always an emotional factor so Red Bull India started promoting their brand by endorsing KL Rahul and women cricketer Smriti Mandhana.

The posts state their Authentic Voice and how they have caption the HD Images \& short Videos, along with their links \& \#tags. The authentic content along with perfect \#tags \& mentions can make a post tremendously successful.

They promote their all events through social media platforms. Red Bull not only focuses on cricket they focus on all kinds of sports that can anything like E-sports, Formula car racing, Hockey, Badminton, Chess etc.

There is a direct link between sports and energy drinks so Red Bull endorsed sports person who can correctly define the strengths and benefits of the energy drink. The sports persons like Ankit Panth, KL Rahul, Smriti Mandhana, Mira Erda, Manpreet Singh who not only promote Red Bull and also influence consumer to consume Red Bull.

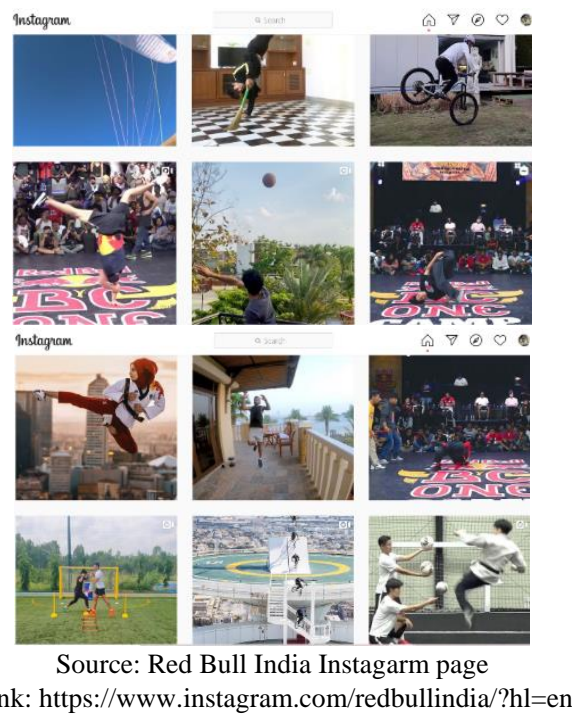

\section{5) Red bull Twitter}

Eye-catching graphics and copy writing posts from Red Bull dominated Social Media's channels, making them even more attractive.

Red Bull India has 143.3k followers on its Instagram page for Red Bull India up to now (08.09.2020).

They support the prominent sports people for whom they 
endorsed their brand through their Instagram accounts.

In September, as Dream 11 IPL starts Red Bull India, it will be launching a Red BullTV promotion, where Rajasthan Royals will be able to look at their favorite players' inner stories.

(A season, a story, a family. Flexed biceps \#InsideStory, out now on \#RedBullTV Television | @ rajasthanroyals Head to http://redbull.in/rajasthanroyals to watch it now. Cricket bat and ball)

Cricket is still an emotional aspect in India, so Red Bull India began to endorse the brand there by supporting KL Rahul and Smriti Mandhana, women cricket makers.

The posts demonstrate their original voices and their connexions and \# tags for the HD photos \& short videos. A post can be immensely effective with credible material and great tags \& mentions. Tags like:

\#givesyouwings,

\#RedBullMEO,

\#PUBG,

\#RedBullPremieres,

\#RedBullFlick,

\#RedBullOffTheRoof

Red Bull uses event name as their tags so audience can easily recognise the events.

Through the use of the social media, they encourage the activities. Red Bull focuses not only on cricket, but also on all sorts of activities such as E-sport, Formula Football, Basketball, Badminton and Chess.

Sports and energy drinks have a strong correlation, but Red Bull helps athletic people who can better identify the benefits and drawbacks of an energy drink. Sports people like Ankit Panth, KL Rahul, Smriti Mandhana, Mira Erda and Manpreet Singh are not only promoters of Red Bull but also the customer.

Red Bull claims to have analysed objectively the benefits and disadvantages of each media channel, and the kind of user they use in each social network. You know what to write, what to post and for whom to post and how to post effectively and on what medium and time is necessary.



Source: Red Bull India Twitter page Link:

https://twitter.com/redbullindia?ref_src=twsrc\%5Egoogle\%7Ctwcamp\%5Eser $\mathrm{p} \% 7 \mathrm{Ctwgr} \% 5$ Eauthor

\section{B. Mountain Dew}

1) Mountain Dew journey in India

Mountain dews is a soft drink brand belonging to the giant PepsiCo soda group. It is one of the most popular neon yellow sodas containing caffeine. The success and excellent mix of the drink have produced waves.

It is very interesting to revolutionize the system. The first cocktail recent was made in 1940 by Tennessee soda bottlers Barney and Ally Hartman. The initial soda was planned as a whiskey accompaniment. In 1932, Brothers Barney and Ally Hartman began the liqueur chaser in Knoxville, Tennessee, to bottle a lemon-lime soda. The flavour of the beverage increased in formulas and composition.

Mountain Dew's 2019 camp celebrates an exhilarating adventure of real-life heroes Gerrari off-roaders, Virdi and Kirpal Singh Tung. 'Chance Utha, Naam Bana' is based on the deep belief that greater success demands more chances. Mountain Dew offers true legends with its iconic biopic style, genuine and inspiring narratives. This time the history of the first $4 \times 4$ Indian world champions is told by Hrithik Roshan. This shooting was an experience in the middle of rainforests. These men's road is full of grain and trash. This Mountain Dew film embraces the feeling of challenge and desire to make a reputation that encourages the audience to do likewise. The Gerrari Offroaders themselves claim that when they see themselves as the underdogs, they make up for what they might lack of money.

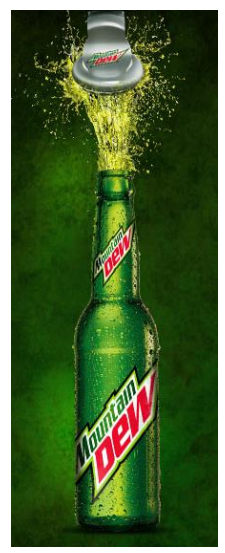

\section{2) Social Marketing of Mountain Dew}

Mountain Dew has been updated and strengthened with its strong social media and web presence. The planet's interactive and social networks content strategy is interesting. There are numerous tournaments that consumers win every day. Mountain Dew products are also available digitally, establishing a presence in many e-commerce businesses, including in online purchase.

There are three types of influencers for Mountain Dew which are part of the marketing campaign. They have Hrithik as the influencer of celebrities with TVC as an anchor. They deal also with mountaineers, mountain bikers and gaming influencers. 
The ideology of the Mountain Dew company has remained the same all this time, even though it is said to be more or less stable.

Mountain Dew's new TVC features brand ambassador Hrithik Rohan and has been shot by Siddharth Anand.

3) Mountain Dew is saluting the risk takers of India through their social media platforms

Mountain Dew's Risk Takers of India ad campaign will showcase the stories of Deepa Malik, Archana Sardana, Arjun Vajpai, Satyendra Verma and Bhakti Sharma.

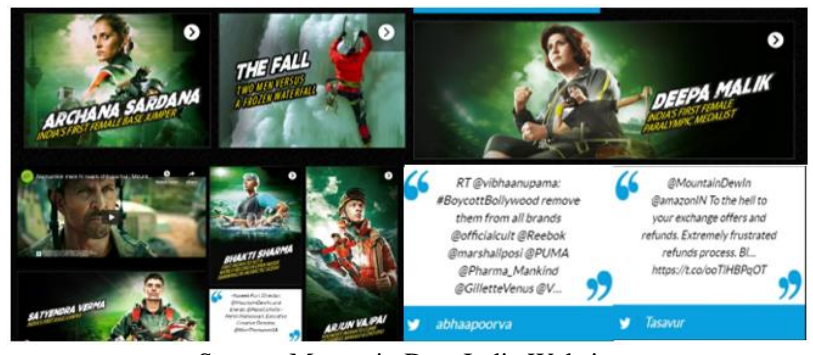

Source: Mountain Dew India Website

(Link: https://www.mountaindew.in/risk-takers.php)

Mountain Dew is all set to bring its philosophy of 'Naam Bante Hain Risk Se' to life through an initiative that salutes the real Risk Takers of India.

The brand has always inspired customers to get out of the ordinary and the launch of the Indian Risk Takers Network aims to inspire the country with tales of true Indian legends, ordinary people who have taken exceptional risks to make a mark. The brand has always inspired people to rise from the ordinary and the introduction of the Risk Taking of India platform aims to empower the country with stories of true Indian heroes.

Mountain Dew take a route never taken in advertising-a biopic to take the story to people across India. For the first time ever in its advertising and in a reiteration of its commitment to bring authenticity and purpose to its brands, the Mountain Dew campaign have superstars Hrithik Roshan essay the role of one of the six real Risk Takers of India. The film shows the brand ambassador live a day in the life of one these Risk Takers as they go about their heroic initiative of being the first Indian to sail the world solo.

Mountain Dew Risk Takers of India will showcase the stories of five real life risk takers - Deepa Malik, Archana Sardana, Arjun Vajpai, Satyendra Verma and Bhakti Sharma. Each of the five heroes recognized by Mountain Dew have overcome hardships and risked their lives to rise above the ordinary and make a name for themselves.

4) Facebook, Instagram \& Twitter

The advertising style through this three social media website are almost same. So we marge them together for better understanding.

Facebook:

Mountain Dew India has 1.9M followers and 2M likes on its facebook page for Mountain Dew India up to now (08.09.2020).

\section{Instagram:}

Mountain Dew India has posted 493 post and got $28.8 \mathrm{~K}$ followers on its Instagram page for Mountain Dew India up to now (08.09.2020).

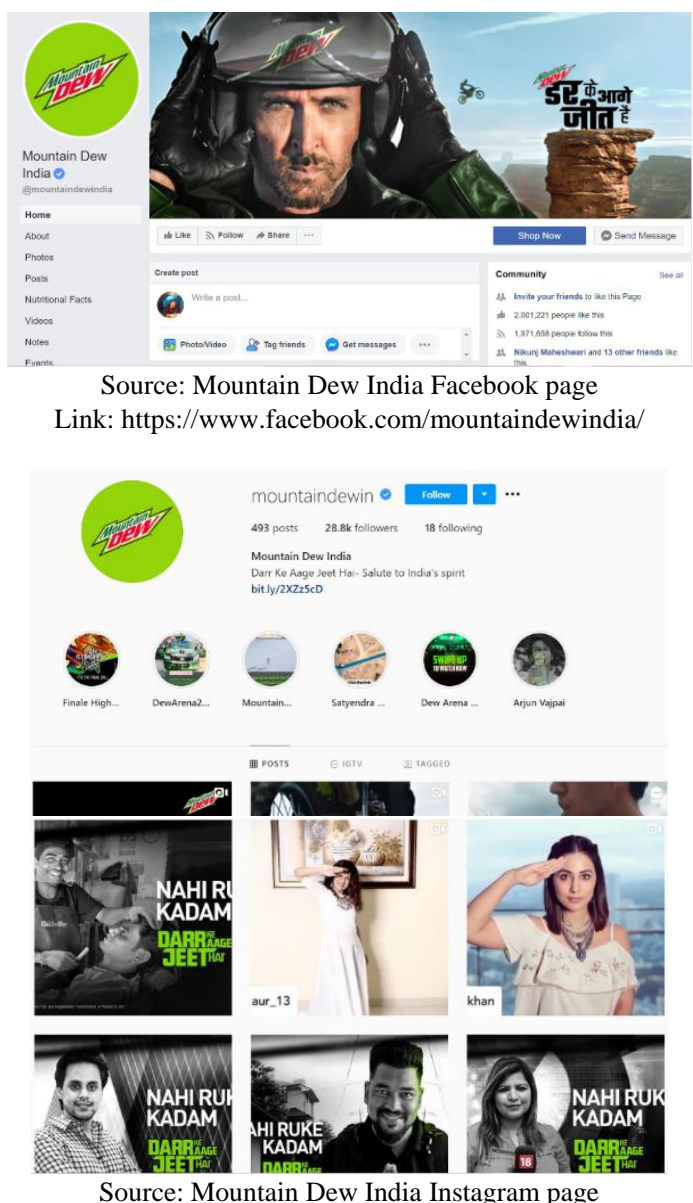

Link: https://www.instagram.com/mountaindewin/?hl=en

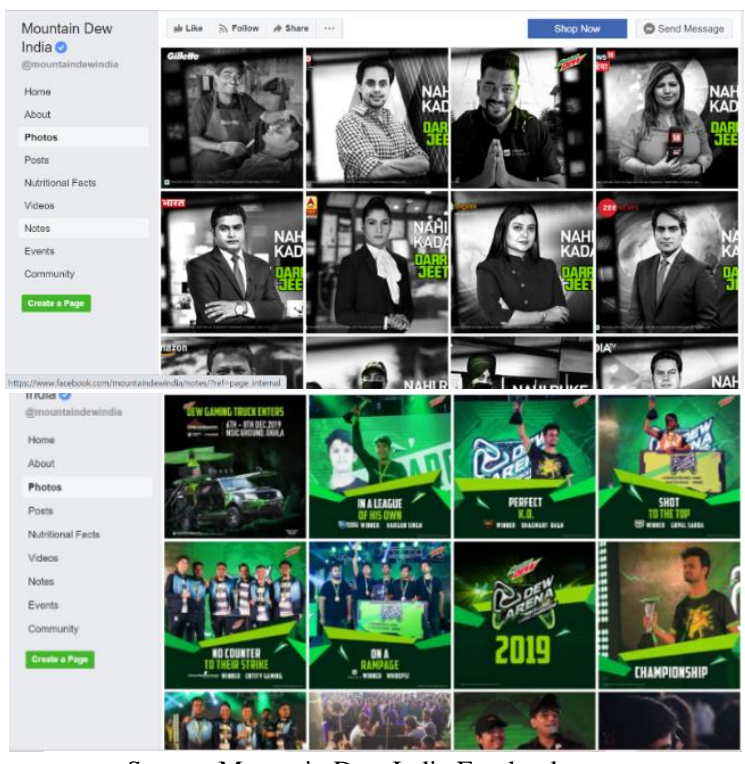

Source: Mountain Dew India Facebook page (Link: https://www.facebook.com/mountaindewindia/) 


\section{Twitter:}

Mountain Dew India has posted 1740 post and got 27.4K followers on its Instagram page for Mountain Dew India up to now (08.09.2020).

5) Social media advertising of these three Facebook, Instagram \& Twitter

On this $73^{\text {rd }}$ Independence day Mountain Dew India launched a unique campaign Nehi Ruke Kadam, Darr ke aage Jeet Hai (\#DarrKeAageJeetHai \#JeetengePhirse) Through this campaign Mountain Dew India salutes Gillette India for supporting and taking care of barbers under the program of \#GilletteBarberSuraksha.

They also salute Red FM, Urban Company, News18 India, Republic Bharat, ABP News, Zee Hindusthan, Zee News, Amazon India, Pizza Hut, Subway, India TV, Vistara, Burger King, Dunzo for being so supportive and always be there for every Indians. They also launched a video and a song "Desh ki sadiyon se yehi reet hai ji, Harr Darr ke Aage Jeet Hai Ji" which is sang by Sukhwinder Sing. Through this video Mountain Dew Salutes the resilient spirit of this country.

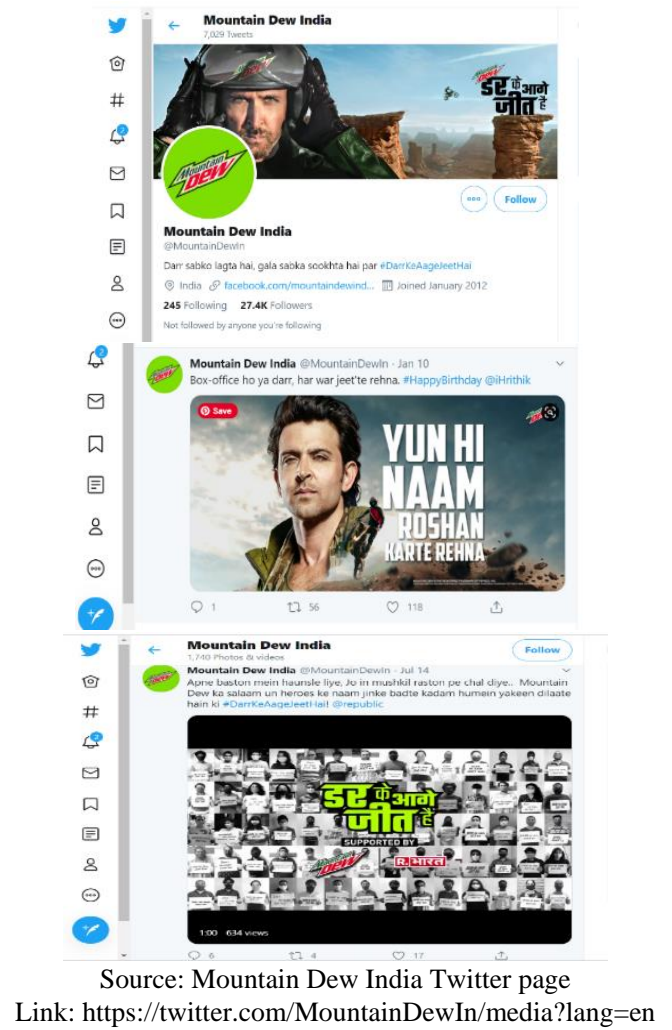

After this campaign the followers of Mountain Dew India facebook pages increased from $78 \mathrm{k}$ to $1.9 \mathrm{M}$ and likes increased from $81 \mathrm{k}$ to $2 \mathrm{M}$.

For their Instagram page they used social media influencer like Hina Khan, Sargun Mehata, Sidharth Sukla to salute all heroes of our country.

Mountain Dew India also organized many gaming events like Dew Arena, PUBG Championship, Truck racing. Through this events Mountain Dew attract to many audiences to their social media handles and create more awareness among Indians about this brand which ultimately help them to grow their business in India. They always promote their through sponsoring event mainly gaming events.

Hashtags used on their Instagram posts:

\#RiskUthaNaamBana,

\#Adventure,

\#India,

\#RoadAdventure,

\#DewArena2019,

\#DewArena,

\#eSports,

\#onlinegaming,

\#gaming,

\#mountaindew.

Hashtags used on their Twitter account:

\#RiskUthaNaamBana,

\#DreamHack2019,

\#DewArena,

\#DewArena2019,

\#pubg,

\#eSports,

\#onlinegaming,

\#gaming,

\#mountaindew.

6) YouTube

Mountain Dew India has got 226K subscriber. They divided their videos into four series.

The four series are:

Naam Hi Inaam Hai

- Kangchenjunga Calling

- Mountain Dew TVC's

- $\quad$ Risk Takers of India

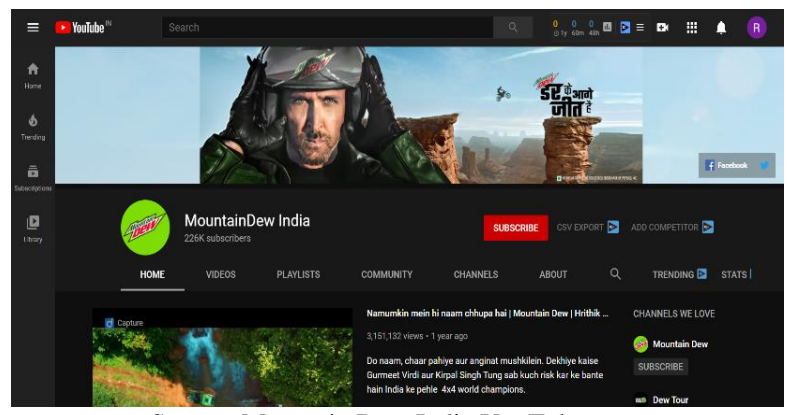

Source: Mountain Dew India YouTube page

Link: https://www.youtube.com/user/MountainDewIndia/featured

Under Naam Hi Inaam hai series they promoted Aishwarya Pissay (India's 1st ever female Bajaj World), Yuvraj Konde Deshmukh (India's youngest motocross campaign). Through this campaign Mountain Dew wants to prove that the names of these risk takers are the biggest gift of their life and their name is enough to prove themselves and achieve their goals.

Under Kangchenjunga Calling series they promote Arjun 
Bajpai. Mountain Dew introduce Arjun Bajpai, a climber who climbed $8000+$ peek at the age of 24 and become the youngest climber who climbed Kangchenjunga. Through eleven episodes Mountain Dew India shows his journey to become the youngest climber of Kangchenjunga.

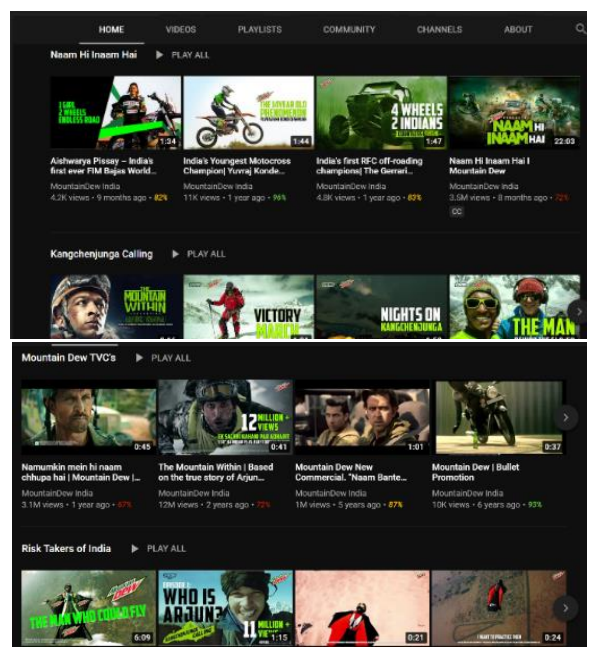

Source: Mountain Dew India YouTube page

Link: https://www.youtube.com/user/MountainDewIndia/featured

Under Mountain Dew TVC's they posted the video of the TV commercials where they showcased Hrithik Roshan, brand ambassador of Mountain Dew as a risk taker and promote their brand.

Under Risk Takers of India series Mountain Dew India state examples of achievers like Deepa Malik, Archana Sardana, Arjun Vajpai, Satyendra Verma and Bhakti Sharma. Mountain Dew's Risk Takers of India ad campaign will showcase the stories of these risk takers.

\section{Gatorade}

\section{1) Gatorade journey in India}

PepsiCo India launch its best-selling brand, Gatorade, an energy drink with global sales of over $\$ 1$ billion. Gatorade will be Pepsi's second major brand launch in two years.

Gatorade Sports Energy Drink was designed to re-energize sportsperson. It is a scientifically developed formula, which comes with a balanced combination of fluids, flavour, electrolytes and carbohydrates to rehydrate and refuel you after an intense game. Gatorade claims their product hydrates better than water because of these additional ingredients.

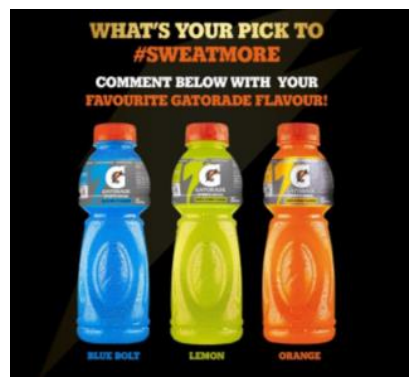

\section{2) Social Marketing of Gatorade}

Gatorade India mainly promote there is sports segment and collaborate with famous Indian sportspersons like: PV Sindhu, Hima Das, Niraj Chopra.

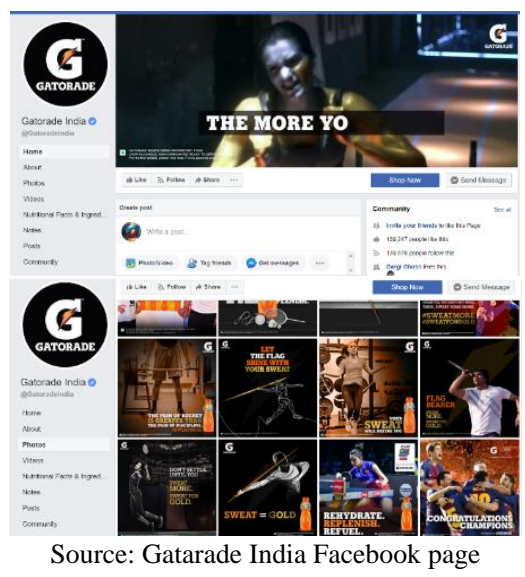

\section{3) Facebook \& Instagram}

The advertising style through these three social media websites are almost same. So we marge them together for better understanding.

\section{4) Facebook}

Gatorade India has $139 \mathrm{k}$ followers and $139 \mathrm{k}$ likes on its facebook page for Gatorade up to now (08.09.2020).

\section{5) Instagram}

They promoting their brands by endorsing famous Indian sports person like PV Sindhu, Hima Das, Niraj Chopra.

They promote Gatorade through some campaigns like: Gatorade Fitness Challenge, Gatorade Victor, nothing beats Gatorade etc.

In this campaigns Gatorade India highlight strength and stamina of Indian sports persons. It also promotes workout from home through the tagline call "Stop the excuses start the exercise".

Gatorade promote their brand as an official sports drink plays their brand in the success story of many athletes. In different kind of sports like Football, Cricket, Badminton, Table Tanis, Javelin Through.

Overall, they are spreading positivity to the youth through their Facebook Page. Hashtag Used for Facebook:

\#NothingBeatsSindhu

\#NothingBeatsGatorade

\#GatoradeFitnessChallenge

\#WorkoutFromHome

\#NothingBeatsGatorade

\#SweatMore

\#TokyoOlympics2020

\#NeerajChopra

Hashtag Used in Instagram:

\#NothingBeatsSindhu

\#NothingBeatsGatorade 
\#GatoradeFitnessChallenge

\#WorkoutFromHome

\#NothingBeatsGatorade

\#SweatMore

\#TokyoOlympics2020

\#NeerajChopra.



\section{6) YouTube}

Gatorade India has $9.24 \mathrm{k}$ subscriber Gatorade on YouTube page and 40M views up to now (08.09.2020).

Through YouTube they promote their brand by doing short interviews of footballers who belongs to different Indian football clubs like: Chennaiyin FC, Mumbai City FC, Delhi Dynamos.

They also promote through international clubs in different sports.

They promoting their brands by endorsing famous Indian sports person like PV Sindhu, Hima Das, Niraj Chopra.

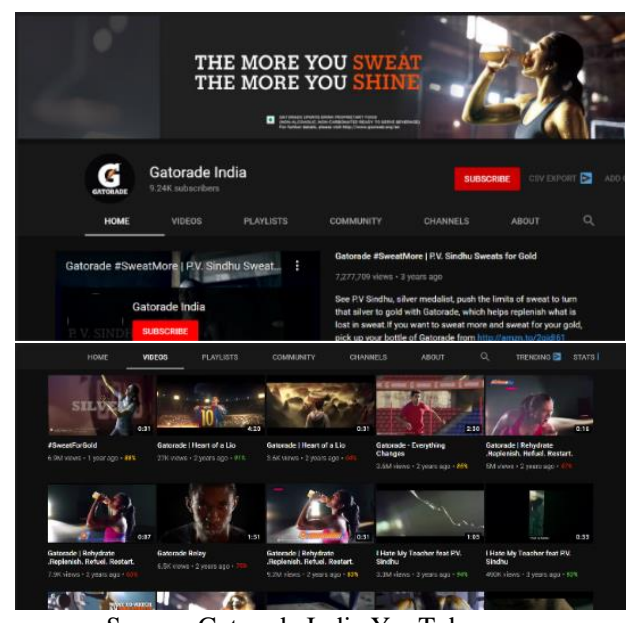

Source: Gatorade India YouTube page

\section{Sting}

\section{1) Sting Journey in India}

Sting Energy Drink is a carbonated energy drink from PepsiCo International and produced by Rockstar Inc. Sting is available in three flavours, such as original Gold Rush, Gold (with Ginseng), Power Pacq (Gold Rush with Malunggay), Power Lime (Kiwifruit/Lime) and Berry Blast (Strawberry).

PepsiCo India Holdings Pvt. Ltd, the local arm of American food and beverages company PepsiCo Inc., has launched energy drink Sting, one of its global brands, across organized retail outlets.

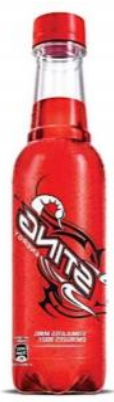

Sting promoted Itself as a less priced energy drink in Indian energy drink market.

2) Social Media marketing of Sting

a) Facebook

Sting India has $15 \mathrm{k}$ followers and 15k likes on its Facebook page for Sting India up to now (08.09.2020).

- In Facebook, sting try to promote its taste as well as efficient energy.

- $\quad$ Sting India promote its lower price category bottle and try to target bigger market.

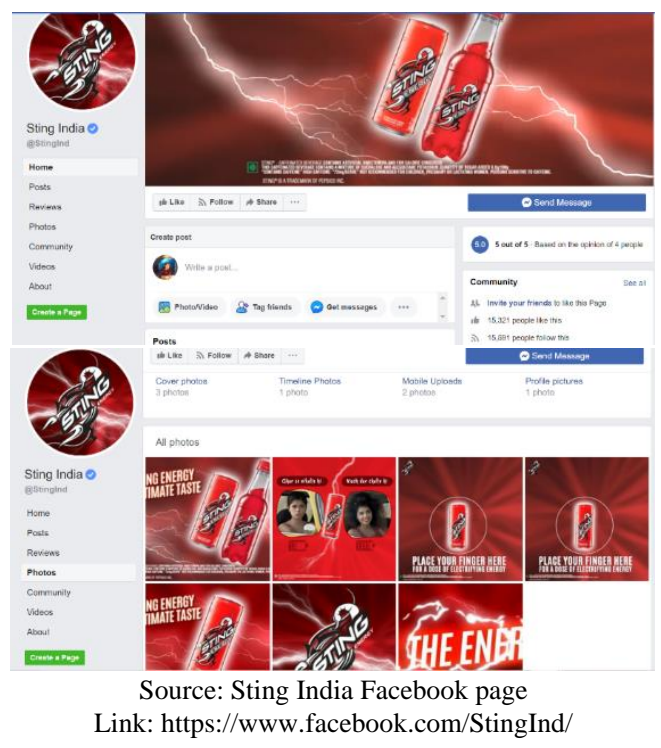

b) Instagram

Sting India has 1282 followers and 15k likes on its Instagram page for Sting India up to now.

- In Instagram, sting try to promote its taste as well as efficient energy.

- Sting India promote its lower price category bottle and try to target bigger market. 


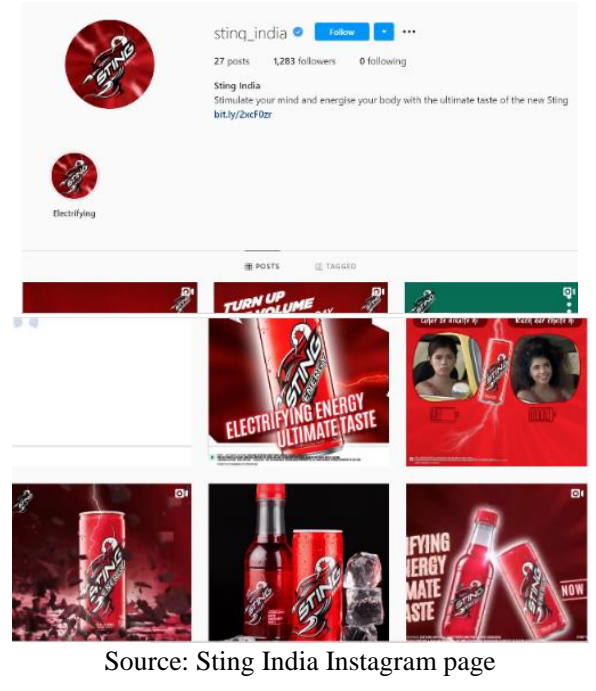

\section{E. Glucon D}

\section{1) Glucon D journey in India}

Heinz is an international food and beverage giant headquartered in Chicago and manufactures over 150 products under its name. When it acquired Glaxo India, it gave birth to the product Glucon-D. This drink was marketed heavily for the Indian summers as it quenches the thirst and replenishes the body fluids.

Glucon D as a product is very popular with sports person and patients. This is considered as a health drink for any age group. The main ingredient of this drink is Glucose (99.4\%) which is very healthy and provides instant energy to the body as it is very quickly absorbed. It has sufficient amounts of carbohydrates which the body requires, and it also cools down the body temperatures quickly. This drink is also known to get rid of dehydration.

Glucon D is available in several variants that are equally popular amongst its consumers. Some of them are as follows,

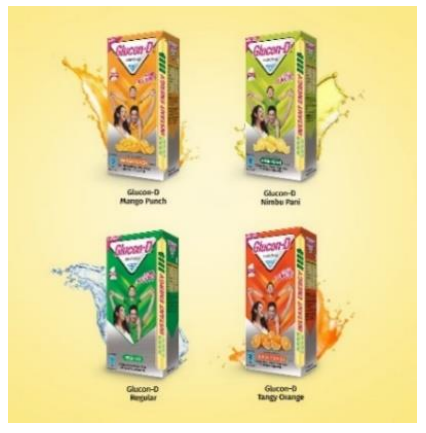

Glucon D Tangy Orange

Glucon D Original Glucon D Nimbus Pani

Glucon D-Orange Blast

Glucon D Aam Panna

Glucon D-Volt

2) Social media marketing of Glucon $D$

Glucon D uses a lot of electronic media to run its campaigns be it television commercials or radio ads. Glucon D has most of time kept sports and children in mind and created ads. These ads are generally seasoned centric (summer), are very relatable and fun to watch.

a) Facebook

Glocon D India has 1,452 followers and 1464 likes on its facebook page for Glucon D up to now (08.09.2020).

Glucon D basicaly promote their brand by just displaying all flavours of Glucon D.

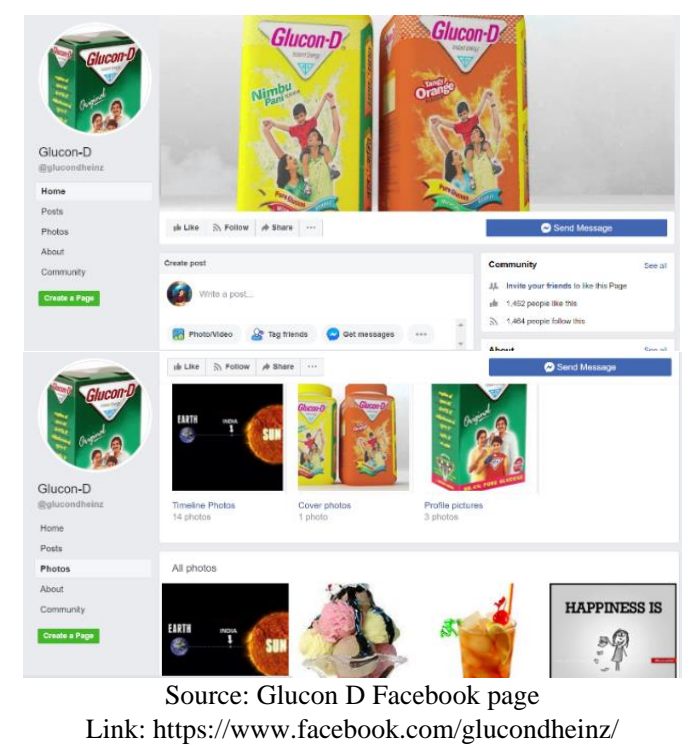

\section{b) Instagram}

Glucon D has got 1725 followers on their Instagram page. On their Instagram page they promote Glucon D as if you want instant energy than you can try Glucon $\mathrm{D}$ and boost your energy and do your work. Glucon D uses has some hashtags like: \#EnergyForEverything \#GluconDForEverything \#Immunity \#energy \#EnergyGharKi \#EnergyOfIndia through which they want to prove that After drinking Glucon D you can get instant energy \& immunity all in one glass.

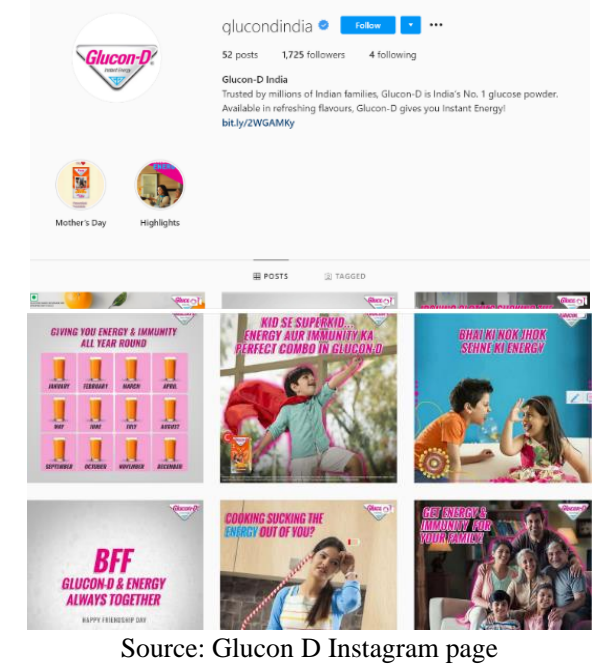

Link: https://www.instagram.com/glucondindia/?hl=en 
c) YouTube

Glucon D doesn't have any YouTube page but they post their TVC's on YouTube. In Summer they launched a campaign in the year 2017 by the brand was called as 'Sirf Paani Nahi, Glucon D Waala Paani.' Through this TVC's they want to convey a massage that one of the kids is extremely fresh and energetic, because he drinks Glucon D Walaa Paani in the summers. They also promoted a campaign called Khel Se Pehele Glucon D where they used tagline "Glucon-D Laga, Energy chadha".


Glucon D TVC: Khel Se Pehele Glucon D

Source: Marketing Strategies of Glucon -D The Energy Booster Link:https://brandyuva.in/2018/09/success-story-of-glucon-dbrand.html\#: :text=Heinz\%20is\%20an\%20international\%20food,and\%20repl enishes\%20the\%20body\%20fluids.

\section{Findings}

In this findings part we are going to highlight the main points which we could find from our research. What we found after studying the social media of each energy drink (Red Bull, Mountain Dew, Gatorade, Sting, Glucon D) is described below:

1) Red Bull: After Studying Red Bull social media handles, we find out that for Red Bull use their social media pages as a weapon to address wide range of consumers. By endorsing sports person, organising events and sponsoring events they want to create more awareness among people. Through they want to reach out as many as possible number of people at a time. For Red Bull India social media plays a great impact their growth and market because though social media they can create more brand awareness which ultimately helps them to grow their market in India.

2) Mountain Dew: We pointed out that Mountain Dew India uses its social media accounts as a tool to target a broad spectrum of customers. They want to build more visibility amongst people by helping sportspeople, hosting activities and funding activities. They share stories of real risk takers of India and wants to inspire common people that anyone can be famous only by their name and work. Through the series which they posted on Risk takers of India they promoted the stories of real heroes of India which inspire people. Though these unique campaigns they promoted their brand and for this campaign they also got many followers on their Facebook page. They try to meet as many people at a time as possible. The social media in Red Bull India have a big effect on their development and demand, since social networks are able to build more visibility of the brand and gradually help them expand their presence in India. They always come up with many different kinds of promotion paly they not only sponsor event or endorsed with celebrities they salute our real heroes of India by their social media handels. Through they increase audience engagement rate to their social media page which help to grow their brand identity and helps to grow more market share.

3) Gatorade: We noticed that after studying social marketing strategies, Gatorade uses its social media pages as a platform to reach a wide variety of consumers with Gatorade. By supporting sportspeople, organizing events and promoting initiatives you want to create more awareness among people. You 're going to reach the highest number of participants. Gatorade India's social networks are having a huge impact on their growth and demand, as social networks will gain more awareness and help them steadily increase their market reach in India.

4) Sting \& Glucon D: Sting and Glucon D mainly focuses on the TV commercials which they promoted on their social media pages. Sting promoted itself as a less priced energy drink that anyone can afford. They promoted this through their social media pages.

Glucon D is brands which we knew form our childhood days. They mainly focused on traditional marketing but now-a-days they promote it by their social media pages. Glucon D positioned itself as a drink which can consumed by every age of consumers. They mainly target children who needs more energy in the summer. Their many TVC's also based on children. They also target every age group of people who needs instant energy.

These ways they promote their brands to grow their market.

\section{Conclusion}

In the current report, which looked at the effect of social media ads on consumer brand tastes, we introduced. Social networking as an interactive market space where advertisers and brand managers are best able to interact, connect and affect customer decision-making on brands (high energy drinks). This is critical as it is.

The new task of marketers is to recognize that marketing is driven by customers and that customers are important elements in marketing. 
In this current scenario when everyone is looking for a hygienic option. Everyone trying to stay feet. Here is a chance of an eventual growth of energy drink market. There are popular energy drinks like Red Bull, Gatorade, Sting, Mountain Dew.

All companies are targeting people through various strategies like Cost cutting, endorsing celebrities, Sponsoring different sports. Through social media handles popular brands influencing people and they are doing it very effectively.

By concluding the whole topic, we would like to say in this world where the effect of social media is on peak. Social media advertising will be the future platform where all the companies will make a try to establish their footprint.

In our study it is completely defined that, the energy drink company like Red Bull and Mountain Dew who did excellent job in terms of advertising and very much active in their social media handles. These companies are successful in influencing people in this upgrowing segment call Energy Drink.

Social media stands as an essential tool in today's market. Which really made an impact in energy drink market. The Indian Energy Drink market is expected to rise at a CAGR of $9.22 \%$ over the $2020-2025$ forecast period.

\section{References}

[1] Anon., 2013. Pepsi to bring Gatorade to India. [Online] Available at:

https://www.business-standard.com/article/companies/pepsi-to-bringgatorade-to-india-

104032701059_1.html\#: :text=PepsiCo\%20India\%20is\%20all\%20set,b illion\%2C\%20in\%20the \%20 country\%20soon.\&text=In\%202001\%20Pe psi $\% 20$ had $\% 20$ introduced,for $\% 20 \mathrm{a} \% 20300 \% 20 \mathrm{ml} \% 20 \mathrm{bottle}$

[2] Anon., 2020. How influencers helped Mountain Dew expand the scope of a TVC.

[Online] Available at: http://www.socialsamosa.com/2020/03/mountaindew-tvc-influencers/

[3] Anon., 2020. India Energy Drink Market - Growth, Trends Forecast (2020 - 2025).

[Online] Available at: https://www.reportlinker.com/p05867466/IndiaEnergy-Drink-Market-Growth-Trends-Forecast.html?utm_source=PRN

[4] Anon., 2020. India Energy Drink market is projected to grow at a CAGR of $9.22 \%$ during the forecast period, 2020-2025.

[Online] Available at: https://www.prnewswire.com/news-releases/indiaenergy-drink-market-is-projected-to-grow-at-a-cagr-of-9-22-during-theforecast-period-2020-2025--301073097.html

[5] Anon., n.d. Energy Drink Wikipedia.

[Online] Available at: https://en.wikipedia.org/wiki/Energy_drink

[6] Anon., n.d. Gatorade India Facebook Page.

[Online] Available at: https://www.facebook.com/GatoradeIndia/

[7] Anon., n.d. Gatorade India Instagram Page.

[Online] Available at: https://www.instagram.com/gatoradeindia/?hl=en

[8] Anon., n.d. Gatorade India Twitter Page.

[Online] Available at: https://twitter.com/gatoradeindia?lang=en

[9] Anon., n.d. Gatorade India YouTube Page.
[Online] Available at:

https://www.youtube.com/user/GatoradeIndia/videos

[10] Anon., n.d. Glucon D Facebook Page.

[Online] Available at: https://www.facebook.com/glucondheinz/

[11] Anon., n.d. Glucon D Instagram Page. [Online] Available at: https://www.instagram.com/glucondindia/?hl=en

[12] Anon., n.d. History \& Marketing Strategies of Mountain Dew. [Online] Available at: https://brandyuva.in/2019/08/marketing-strategies-of-mountaindew.html

[13] Anon., n.d. Marketing Strategies of Glucon -D The Energy Booster. [Online] Available at: https://brandyuva.in/2018/09/success-story-of-glucon-dbrand.html\#: : :text=Heinz\%20is\%20an\%20international\%20food,and\% 20replenishes\%20the\%20body\%20fluids.

[14] Anon., n.d. Mountain Dew India Facebook Page. [Online] Available at: https://www.facebook.com/mountaindewindia/

[15] Anon., n.d. Mountain Dew India Instagram Page. [Online] Available at: https://www.instagram.com/mountaindewin/?hl=en

[16] Anon., n.d. Mountain Dew India Twitter page. [Online] Available at: https://twitter.com/MountainDewIn/media?lang=en

[17] Anon., n.d. Mountain Dew India YouTube page. [Online] Available at: https://www.youtube.com/user/MountainDewIndia

[18] Anon., n.d. Red Bull GmbH- Wikipedia. [Online] Available at: https://en.wikipedia.org/wiki/Red_Bull_GmbH

[19] Anon., n.d. Red Bull India. [Online] Available at: https://jobs.redbull.com/kz-kk/locations/red-bull-india?lang=en

[20] Anon., n.d. Red Bull India Instagram. [Online] Available at: https://www.instagram.com/redbullindia/?hl=en

[21] Anon., n.d. Red bull India twitter account. [Online] Available at: https://twitter.com/redbullindia?ref_src=twsrc\%5Egoogle\%7Ctwcamp\% 5Eserp\%7Ctwgr\%5Eauthor

[22] Anon., n.d. Red Bull Official Facebook page. [Online] Available at: https://www.facebook.com/RedBull/

[23] Anon., n.d. Sting India Facebook Page. [Online] Available at: https://www.facebook.com/StingInd/

[24] Anon., n.d. Sting India Instagram Page. [Online] Available at: https://www.instagram.com/sting_india/

[25] ETBrandEquity, 2017. This is how Mountain Dew is saluting the Risk Takers of India.

[Online] Available at:

https://brandequity.economictimes.indiatimes.com/news/advertising/this -is-how-mountain-dew-is-saluting-the-risk-takers-ofindia/57872821\#: :text=Mountain\%20Dew\%20Risk\%20Takers\%20of,S atyendra\%20Verma\%20and\%20Bhakti\%20Sharma.

[26] Joyce, P. R. \&. R., 2017. Impact of Social Media Advertising On High Energy Drink Preferences and Consumption. The Journal of Applied Business Research, Volume 33, p. 16.

[27] Mitra, S., 2017. PepsiCo brings energy drink Sting to India. [Online] Available at: https://www.livemint.com/Industry/bu13uKzeB3IKhNpYgqcGGP/Pepsi Co-brings-energy-drink-Sting-to-India.html

[28] Soni, V., 2015. How Red Bull Uses Social Media as The Key Platform to Build Its Brand.

[Online] Available at: https://www.digitalvidya.com/blog/how-red-bulluses-social-media-as-the-key-platform-to-build-its-brand/

[29] Wikipedia, n.d. Sting Energy Drink-Wikipedia. [Online] Available at: https://en.wikipedia.org/wiki/Sting_Energy_Drink 